$$
\begin{aligned}
& \text { 우리나라 제주도에서 관찰된 바다거북의 좌초와 혼획 } \\
& \text { 정민민 }^{\star *} \cdot \text { 문대연 }^{\star \star} \cdot \text { 김성호* }{ }^{\star} \text { 김흥수 }{ }^{*} \text { 김재우 }{ }^{*} \\
& \text { ( }{ }^{\star \star} \text { 국립수산과학원 · }{ }^{\star \star} \text { 국토해양부) }
\end{aligned}
$$

\title{
Observation and Record of Sea Turtles in Bycatch and Stranding from Jeju Island of Korea
}

\author{
Min-Min JUNG ${ }^{*+} \cdot$ Dae-Yeon $\mathrm{MOON}^{* *} \cdot$ Seong-Ho KIM${ }^{*} \cdot$ Heung-Soo KIM ${ }^{*} \cdot$ Jae-Woo KIM ${ }^{*}$ \\ $\left({ }^{\dagger *}\right.$ National Fisheries Research \& Development Institute $\cdot{ }^{* *}$ Marine Biodiversity Institute)
}

\begin{abstract}
Bycatch and stranding of sea turtles from Jeju coastal water of Korea were monitered from 2008 to 2009. A total of 41 sea turtles, consisting of 12 greens (Chelonia mydas), 3 loggerheads (Caretta caretta), 1 hawksbill (Eretmochelys imbricata) and 25 unidentified species, were recorded and observed in those area. Reported stranding and bycatch reached to a peak in August. The largest number of bycatch occurred in the coastal waters around Aewol-eup located in northwest area of Jeju Island. Most of the bycatch were taken by set nets and gill nets, which prevailed over the fishing grounds in the coastal waters of the Jeju Island. It is suggested that an appropriate monitoring system be necessary to conserve endangered sea turtle species in Jeju of Korea.
\end{abstract}

Key words : Bycatch, Green sea turtle, Hawksbill sea turtle, Jeju, Loggerhead sea turtle, Sea turtle, Stranding

\section{I. 서 론}

바다거북은 해양에 서식하는 파충류의 일종으 로 지구상에는 2 과 8 종의 바다거북이 존재하는 것으로 알려져 있으나, 최근에는 종래 검은바다 거북(Black sea turtle, Chelonia agassizii)으로 불리 었던 1 종의 분류학적 재검토를 통하여 지금은 2 과 7종의 바다거북이 존재한다는 보고가 있으며 이들은 주로 태평양과 인도양, 대서양의 열대와 아열대 해역에 주로 서식하지만 일부 종은 온대
해역에서도 관찰되고 있다(Marquez, 1990). 우리 나라에서는 푸른바다거북(Green sea turtle, Chelania mydas), 붉은바다거북(Loggerhead sea turtle, Caretta caretta), 장수바다거북(Leatherback sea turtle, Dermochelys coriacea) 그리고 매부리바다거북 (Hawksbill sea turtle, Eretmochelys imbricata)의 4 종 이 출현하는데 주로 푸른바다거북(C. mydas)과 붉 은바다거북(C. caretta)이 대부분을 차지하는 것으 로 알려져 있다(문 등, 2009).

바다거북은 1970년대까지만 해도 바다거북의

\footnotetext{
† Corresponding author : 064-764-6061, jminmin@korea.kr

* 이 연구는 국립수산과학원(RP-2011-AQ-057)에서 국토해양부의 보호대상 해양생물 보전 연구와 관 상생물 품종개발 및 양식기술개발 연구의 일환으로 수행되었습니다. 이 연구를 수행함에 있어서 도움을 주신 제주도 어업인과 제주해양경찰서, 각 읍면사무소 관계자 여러분에게 감사드립니다.
} 
알과 근육부를 식용으로 이용하거나 오일 제조, 등갑 공예용 등 여러 가지 산업적인 목적으로 자 연으로부터 채포되어 이용되었다(Bustard, 1970). 이와 같은 바다거북 남획 행동은 바다거북 생물 량의 급격한 감소를 초래하였으며, 그 결과 CITES (The Convention on International Trade in Endangered Species of Wild Fauna and Flora; 멸종위기에 처한 야생동식물 및 그 생물상 의 국제거래에 관한 협약) 부속서 I 에 등재되어 전 세계적으로 보호 관리되고 있다. 이와는 별도 로 멸종위기에 처한 바다거북의 보호를 위하여 2004년도에 UN의 Food and Agriculture Organization(FAO)에서는 바다거북을 보존, 관리 하기 위한 지침을 개발하여, 각 국제수산기구에 권고 종용한 바 있으며(FAO, 2005), 이에 따라 각 지역수산기구에서도 자체 보존 조치안을 채택 시행하고 있다(IATTC, 2006; WCPFC, 2008).

그러나 온대지역에 속하는 우리나라 해역에서 는 바다거북에 대한 현황파악 조차도 이루어지지 않았고 학술적인 연구도 거의 진행되지 못하였 다. 하지만 우리나라에서도 비정기적이고 불규칙 적이지만 바다거북의 산란행동이 관찰 기록되어 있으며 붉은바다거북의 산란이 이루어진 장소는 우연산란장(偶然産卵場, accidental nesting place) 으로 적합한 산란환경을 갖추고 있었다(정 외, 2012). 뿐만 아니라 최근 들어 우리나라 연안 특 히 바다거북의 우연산란장이 확인된 제주도 연안 에서는 바다거북이 혼획 또는 좌초되는 사례가 점차 증가하고 있어 이에 대한 보호 대책 수립이 시급한 실정이다.

이 연구는 국토해양부의 '멸종위기 해양동물 바다거북 보호사업'의 일환으로 수행되었으며, 본 논문은 2008년도에서부터 2009년까지 제주도 연 안 해역에서 실시한 바다거북에 대한 혼획 및 좌 초 결과를 보고하고자 한다.

\section{II. 재료 및 방법}

제주도 연안 해역에서 2008년부터 2009년까지 2년간 실시된 바다거북의 혼획 및 좌초 조사는 제주도의 연안 해역에서 추자면을 제외한 행정구 역별(2개 시, 7 개 읍, 4 개 면 등) 13 개 해역으로 구분하여 실시하였으며, 최초 발견한 어업인이나 이들로부터 신고 받은 해양경찰서에 의해 국립수 산과학원 미래양식연구센터에 신고 되어 이루어 졌다. 이에 따라 연구원이 직접 현장에서 혼획 및 좌초된 바다거북의 생물학적 자료를 수집하거 나 좌초 사망원인을 분석하기 위하여 실험실로 운반하는 등의 조치가 이루어졌다.

생물학적 조사는 가능한 현장에서 바로 이루어 졌으며, 혼획 및 좌초 일시, 장소, 바다거북의 종 류, 성별, 크기 등을 신고자로부터 확인하거나 연 구자가 직접 측정하였다. 혼획, 좌초된 바다거북 의 생물학적 특징은 일반 반사식 카메라(Sony, Japan)를 이용하여 촬영 분석 하였으며, 크기는 줄자를 이용하여 등딱지의 길이를 머리 뒷부분에 서 꼬리 윗부분까지의 곡갑장 $(\mathrm{CCL}$; Curved Carapace Length)과 등딱지의 폭이 가장 넓은 부 위의 길이인 곡갑폭(CCW; Curved Carapace Width)을 $0.1 \mathrm{~cm}$ 단위까지 측정하였다. 혼획 및 좌초 자료는 월별, 어구별, 그리고 해역별로 정리 하여 각 종류의 바다거북에 대한 혼획 특성을 분 석하였으며, 혼획 어구는 정치망, 자망(걸그물) 및 좌초로 구분하여 정리하였다.

\section{III. 결 론}

2008년부터 2009년까지 2년간 실시한 바다거북 의 혼획 및 좌초 조사 결과 우리나라의 제주도 연안 해역에서는 총 3 종 41 마리의 바다거북이 발 견되었다 [Fig. 1]. 2008년도에는 푸른바다거북(C. mydas) 5 마리, 붉은바다거북 $(C$ caretta) 2 마리였 고, 2009년에는 푸른바다거북(C. mydas) 7마리, 붉은바다거북 $(C$ caretta) 1 마리, 매부리바다거북 (E. imbricata) 1 마리가 관찰되었다. 


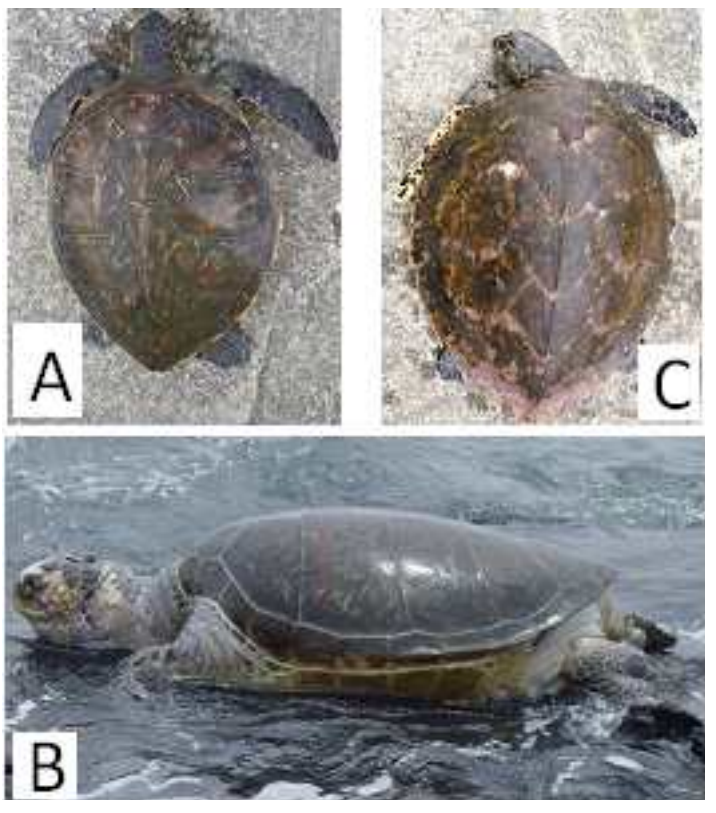

[Fig. 1] Three species of sea turtles caught by bycatch and stranding in Jeju island during 2008 and 2009 period. A; green sea turtle ( C. mydas), B; loggerhead sea turtle ( $C$. caretta) and C; hawksbill sea turtle (E. imbricata) in Jeju island

<Table 1>에서 2년의 조사기간 동안 확인된 41 마리의 바다거북 중에서 가장 많이 혼획 및 좌초된 종류는 푸른바다거북(C. mydas)으로 12 마리가 관찰되어 연구자가 직접 종명을 확인하

$<$ Table $1>$ Species composition of sea turtles observed in the coastal areas of the Jeju island during 2008 and 2009 period

\begin{tabular}{|c|c|c|c|c|}
\hline \multirow{2}{*}{ Species } & \multicolumn{2}{|c|}{ Year } & \multirow{2}{*}{ Total } & \multirow{2}{*}{$\%$} \\
\hline & 2008 & 2009 & & \\
\hline Chelonia mydas & 5 & 7 & 12 & 29.3 \\
\hline Caretta caretta & 2 & 1 & 3 & 7.3 \\
\hline Eretmochelys imbricata & & 1 & 1 & 2.4 \\
\hline Unidentified Species & 9 & 16 & 25 & 61.0 \\
\hline Total numbers & 16 & 25 & 41 & 100 \\
\hline No. of species & 2 & 3 & 3 & \\
\hline
\end{tabular}

지 못한 개체까지 포함하여 관찰된 전체 개체 수의 $29.3 \%$ 를 차지하였으며, 그 다음으로 붉은 바다거북(C caretta)이 3 마리로 $7.3 \%$, 매부리바 다거북(E. imbricata)이 1 마리로 $2.4 \%$ 를 차지하 였다. 연구자가 현장에 접근하기 이전에 어업 인과 주민에 의하여 현장에서 방류되거나 자연 적 유실에 의하여 생물학적 특성을 확인되지 못한 개체는 2008년에 9마리, 2009년에는 16마 리였다.

<Table 1>에 나타낸 것과 같이 2008년에는 16 마리, 2009년도에는 25마리의 바다거북의 좌초와 혼획이 관찰되어 개체수가 증가하였고 종수 또한 2008년도에는 2종이 관찰되었으나 2009년도에는 3종으로 증가하였다. 한편, 미확인된 바다거북은 문답 조사 결과 대부분이 푸른바다거북(C. mydas) 으로 추정되지만 일부 개체는 붉은바다거북 $(C$. caretta)도 포함되었을 것으로 추정된다.

[Fig. 2]와 같이 월별 바다거북의 혼획 좌초 상 황을 정리하여 보면, 2008년과 2009년 2년에 걸 쳐서 관찰된 41 마리의 바다거북 중 가장 많은 혼 획과 좌초가 관찰된 월은 8 월로 전체 좌초 혼획 개체수의 $37 \%$ 에 해당하는 15 마리가 관찰되었고, 6월에 7마리, 7월에는 6마리가 관찰되었다.

월별 관찰 결과에서 1 월, 4 월 그리고 12 월에는 바다거북의 관찰 기록이 없어 제주 연안에서 바 다거북의 관찰은 주로 5 월에서 10 월 사이에 용이 한 것으로 나타났다 [Fig. 2].

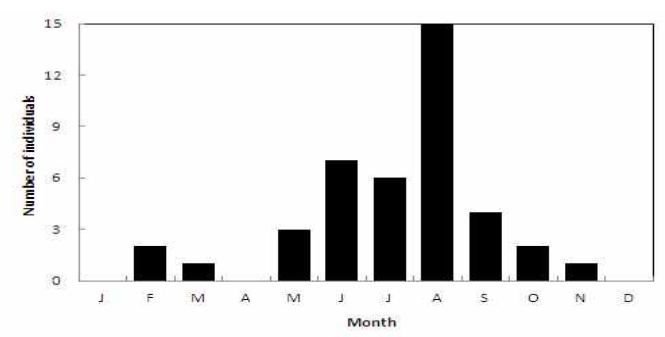

[Fig. 2] The number of sea turtles observed monthly in the coastal areas of the Jeju Island during 2008 and 2009 period 
관찰된 3종의 바다거북을 월별로 나타낸 것이 [Fig. 3]이다. 그 결과 3 종의 바다거북은 월별 출 현 양상이 뚜렷하게 구분 가능하였는데, 푸른바 다거북 (C. mydas)은 여름과 가을에 해당되는 6월 부터 11월까지, 붉은바다거북(C. caretta)은 여름과 초가을에 해당되는 $6,8,9$ 월에 관찰되었다. 하지 만 겨울에 해당되는 2 월에 매부리바다거북 $(E$. imbricata)이 관찰된 것은 매우 특이한 것이다.
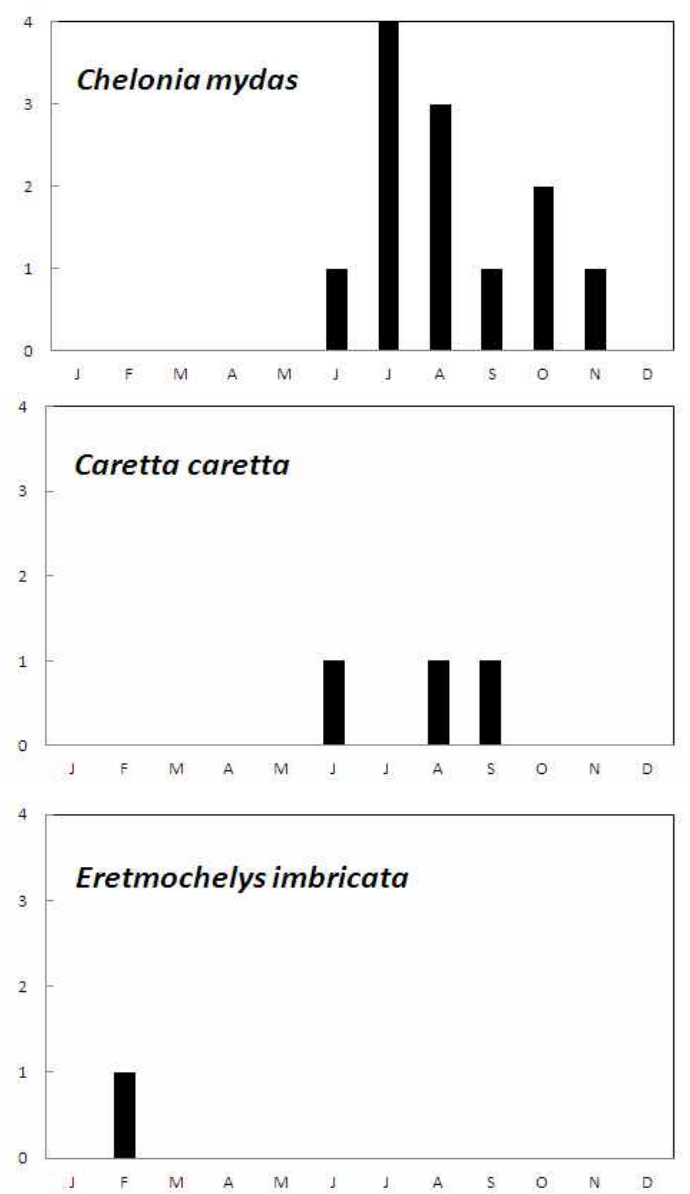

[Fig. 3] The number of identified sea turtles monthly observed in Jeju island

한편, 종명이 확인되지 않은 바다거북의 혼획 과 좌초는 겨울을 제외한 전 기간 관찰이 용이하 였다[Fig. 4].

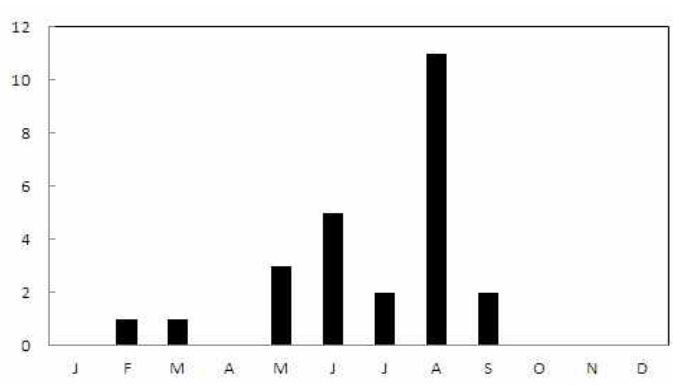

[Fig. 4] The number of unidentified sea turtles observed in Jeju

제주도 연안에서 좌초 혼획된 바다거북의 출현 양상을 제주도의 권역별로 분석한 결과를 [Fig. 5]에 나타내었다. 그 결과, 바다거북의 혼획과 좌 초는 주로 제주도 북서부 연안 해역에서 집중적 으로 혼획 및 좌초되는 경향을 보였다.

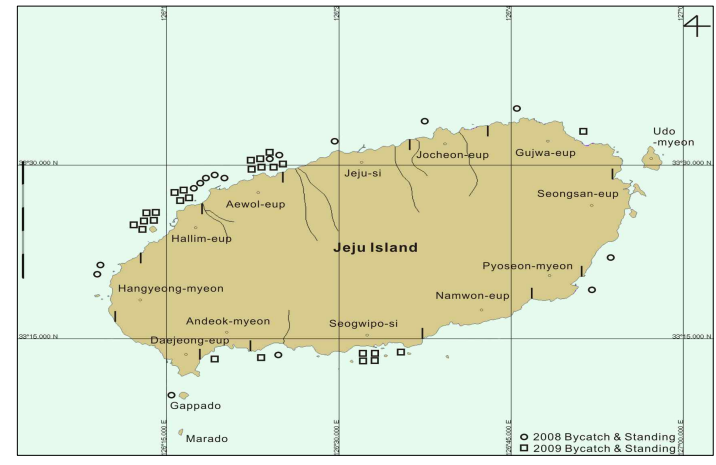

[Fig. 5] Distribution of sea turtles bycatched and stranded in Jeju from 2008 (circles) to 2009 (square)

바다거북의 권역별 혼획과 좌초 사례 분포는 제주도 북서부 해안에 위치한 애월읍 연안 해역 에서 14 마리로 가장 많이 관찰되었으며, 전체 좌 초 혼획 개체수의 $34.1 \%$ 를 차지하였다. 그 다음 으로는 한림읍 연안 해역에서 10 마리( $24.4 \%)$, 서 귀포시에서 7 마리(17.1\%) 순으로 높게 나타났으 며 지역적으로 집중되는 양상이 관찰되었는데 이 3권역을 제외한 나머지 지역에서는 대부분 1-2개 체의 출현이 관찰되었고 제주도 북동쪽에 위치한 
우도면과 제주도 정남쪽에 위치한 남원읍에서는 바다거북의 좌초나 혼획은 관찰되지 않았다 [Fig. 6].

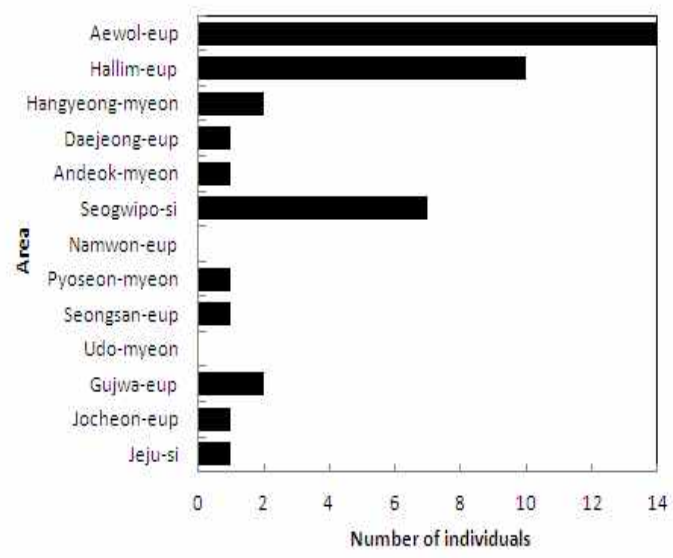

[Fig. 6] Frequency of bycatch and stranding sea turtles observed in each administrative district of Jeju

이 결과는 3 종의 바다거북을 종별로 분석한 결 과에서도 뚜렷한 차이를 나타내었는데, 그 중에 서도 푸른바다거북(C, mydas)은 제주도 북서부 지역에 위치한 애월읍과 한림읍 그리고 한경면에 서 주로 좌초 혼획되었다[Fig. 7].

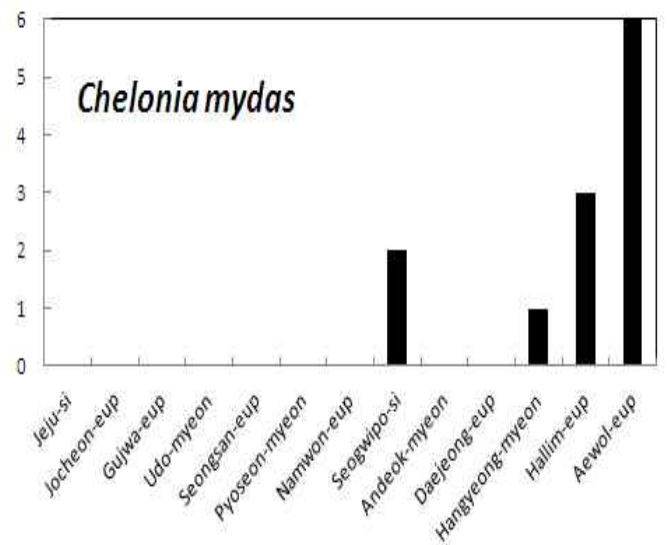

[Fig. 7] Place of bycatch and stranding of green sea turtle ( $C$. mydas) in Jeju
어구별 혼획은 정치망 어구류에서 25마리로 전 체 41마리 중에서 $61.0 \%$ 를 차지하여 가장 많이 혼획되었으며, 걸그물류의 일종인 자망류에서 5 마리(12.2\%), 표류하거나 연안 해안선에 좌초된 개체는 11 마리 $(26.8 \%)$ 가 관찰되어 제주도 연안에 서 좌초 혼획되는 바다거북은 대부분 연안에 설 치된 정치망에 혼획되었다[Fig. 8].

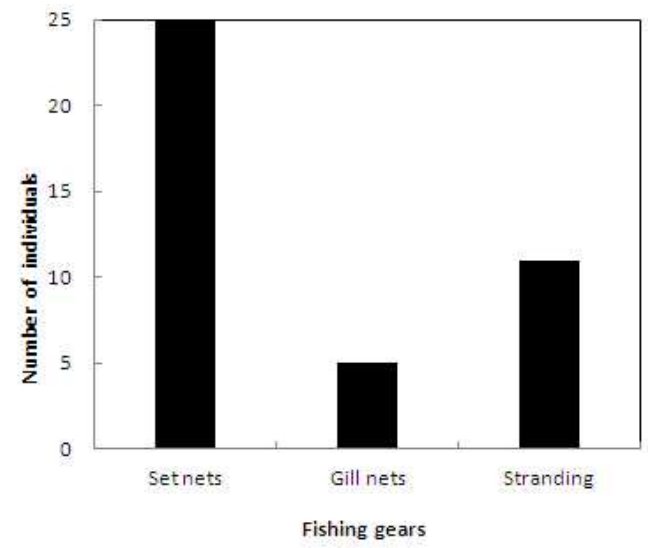

[Fig. 8] Bycatch and stranding of sea turtle by three types, setnet, gillnet and stranding in Jeju

한편, 조사기간 중 혼획 및 좌초된 41마리 바 다거북 중 자위적으로 바다에 나아갈 수 있는 23 마리 $(56.1 \%)$ 는 현장에서 갑장, 갑폭, 무게 등을 측정 후 방류하였으나 6 마리(14.6\%)는 외상, 탈진 그리고 외상 후 출혈이 관찰되어 국립수산과학원 으로 옮겨 치료 관리 후 회복된 개체는 위성추적 장치를 부착하여 방류하였다. 그러나 41 마리 중 에서 12마리는 이미 폐사된 상태로 연안이나 해 상에서 발견되었는데 전체 좌초 혼획 개체수의 $29.3 \%$ 를 차지하였다.

2008년과 2009년 2년에 걸쳐서 우리나라의 제 주도 일원에서 이루어진 바다거북 조사 결과, 푸 른바다거북을 중심으로 붉은바다거북, 매부리바 다거북을 포함한 모두 3종의 바다거북이 혼획 또 는 좌초되었는데, 관찰된 바다거북의 크기를 알 아보기 위하여 곡갑장을 측정한 결과, 가장 많은 
개체가 좌초 또는 혼획된 푸른바다거북 $(C$. mydas)의 경우에는 그 크기가 어린 소형 개체에 서부터 성체 개체까지 다양하게 관찰되었는데, 발견된 푸른바다거북(C. mydas, $\mathrm{n}=12)$ 의 최소 곡 갑장은 $39.2 \mathrm{~cm}$, 최대 곡갑장은 $87.6 \mathrm{~cm}$ 이며 평 균 $61.1 \mathrm{~cm}$ 의 곡갑장을 기록하였다. 한편, 붉은바 다거북(C. caretta, $\mathrm{n}=3)$ 의 경우 최소 곡갑장은 82 $\mathrm{cm}$, 최대 곡갑장은 $91.1 \mathrm{~cm}$ 로 평균 $85.8 \mathrm{~cm}$ 이었 으며, 매부리바다거북(E. imbricata, $n=1)$ 의 곡갑장 은 $41.9 \mathrm{~cm}$ 이었다 <Table 2>.

$<$ Table 2> Curved carapace length $(\mathrm{cm})$ of by-catched and stranded sea turtles in the Jeju, Korea

\begin{tabular}{|c|c|c|}
\hline \multirow[t]{2}{*}{ Species } & \multicolumn{2}{|c|}{$\begin{array}{c}\text { Curved carapace } \\
\text { length }(\mathrm{cm})\end{array}$} \\
\hline & Mean Min. & Max. \\
\hline Chelonia mydas $(\mathrm{n}=12)$ & $\begin{array}{ll}61.1 & 39.2\end{array}$ & 87.6 \\
\hline Caretta caretta $(\mathrm{n}=3)$ & $85.8 \quad 82.0$ & 91.1 \\
\hline Eretmochelys imbricata $(\mathrm{n}=1)$ & $41.9 \quad 41.9$ & 41.9 \\
\hline
\end{tabular}

\section{IV. 고 찰}

바다거북은 일반적으로 제주도보다 남쪽의 수 온이 높은 아열대나 열대 해역에 주로 서식하며 우리나라의 제주도 연안에는 수온이 높은 시기에 일시적으로 출현하는 것으로 추측되어져 왔다. 그러나 이 연구를 통하여 제주도에는 지금까지 예측한 것보다 훨씬 많은 개체 수의 바다거북이 존재한다는 것을 확인할 수 있었다. 특히 겨울철 과 봄철을 제외한 시기에는 예상보다 많은 개체 수의 바다거북이 관찰되었다. 한편, 제주도 연안 에서 연중 어로 작업을 하는 어업인과 해녀를 대 상으로 설문한 결과 겨울철에도 수중에서는 바다 거북이 관찰된다는 것을 감안하면, 사계절 연중 제주도 연안 해역에서 바다거북이 서식하고 있을 것으로 판단된다.

2008년부터 2009년까지 제주도 연안에서 혼획 되고 좌초한 바다거북을 조사한 결과, 확인된 41
건 중 24 건(58.5\%)이 제주도 북서부 연안 해역의 애월읍 연안 해역과 한림읍 연안 해역에서 관찰 되었다. 특히 애월읍 하귀리와 고내리 및 한림읍 귀덕리 그리고 한림읍 비양도 연안 해역에서의 바다거북 출현이 매우 빈번하였다. 이 결과는 애 월읍 연안 해역과 한림읍 연안 해역이 남쪽 해역 으로부터 우리나라에 접근하는 바다거북의 주요 이동 경로가 되고 있음을 시사한다. 특히 제주도 북서부 연안에서 어린 개체를 포함 다양한 크기 의 푸른바다거북(C. mydas)이 관찰되는 현상은 이 지역이 푸른바다거북(C. mydas)의 색이장 또 는 성육장으로 이용되고 있을 가능성이 높다고 볼 수도 있다.

수온과 먹이환경은 바다거북의 이동을 좌우하 는 매우 중요한 요인이다. 결국 바다거북은 생존 과 번식에 적합한 수온대가 형성될 경우 먹이를 쫓아서 이동한다(Gardner et al., 2006). 이러한 바다거북의 행동 습성은 어업활동을 위하여 설치 한 그물에 혼획될 수 있는 원인이 되는데, 트롤 이나 선망 같은 능동적 어구보다는 정치망이나 자망과 같은 수동적 어구에 의하여 혼획이 관찰 되는 것으로 보아 바다거북은 오징어와 같은 먹 이감을 쫓아가다가 어구에 혼획되는 것으로 판단 된다.

Cuba의 카리브해역에 분포하는 푸른바다거북 (C. mydas)을 대상으로 표지 방류하여 어업 활동 중에 포획되는 비율을 조사한 결과, $5.5 \%$ 의 비교 적 높은 결과가 보고되었다(Moncada et al., 2006). 이와 같은 현상은 우리나라의 제주도 연안 에서도 발생 가능한 것으로 앞으로 제주도 연안 에서 발견되는 바다거북에 표지를 부착, 방류하 여 어업활동 중 어느 정도의 개체가 혼획되거나 좌초되는지 조사하여야 할 필요성이 있다.

바다거북이 폐사체의 상태로 연안에 좌초하는 경우가 우리나라에서도 종종 관찰되고 있는데 그 원인에 대해서는 아직 분명하게 밝혀진 것은 없 다. 하지만 발견되는 바다거북의 크기가 성체 이 상 크기이며 일부 개체에서는 체표에 상처가 있 
는 것을 감안하면 대부분 어업 활동에 의하여 폐 사되었을 것으로 추정되고 있다. 인근 일본에서 도 연안 해역에 출현하는 바다거북의 약 $5 \%$ 정 도가 좌초하는 것으로 보고되고 있는데 어구에 의한 손상 가능성이 가장 큰 것으로 파악되고 있 다(Bolton and Witherington, 2003). 한편, 바다거 북이 죽는 원인으로는 수명이 다되어 자연 사망 후 수면에 부상하고 연안으로 좌초되는 경우도 있으며, 질병이나 물리적인 상처 그리고 회유 경 로에서 이탈하여 죽는 경우(Wyneken, 2001)도 많 을 것으로 예상되어 우리나라 연안에서 폐사 개 체 상태로 좌초되는 모든 바다거북이 어업활동에 의하여 폐사되었다고는 할 수 없으며, 오히려 보 다 남쪽의 아열대나 열대해역에서 다양한 원인으 로 페사된 바다거북이 해류에 의하여 수동적으로 이동되어 우리나라 연안에 표착하였을 가능성도 배제할 수는 없다.

푸른바다거북 $(C, m y d d s)$ 과 붉은바다거북(C caretta) 의 경우 산란 가능한 크기는 각각 등갑의 크기 (straight carapace length 기준)가 최소 $81 \mathrm{~cm}$ (Balazs, 1982)와 72 cm (Marquez, 1990)로 알려 져 있다. 제주도 연안 해역에 출현하는 바다거북 의 크기는 푸른바다거북(C. mydas)이 $39.2 \mathrm{~cm}$ $87.6 \mathrm{~cm}$, 붉은바다거북 (C. caretta)이 $82 \mathrm{~cm}$ $91.1 \mathrm{~cm}$ 의 곡갑장 범위를 가지고 있으며, 대부분 암컷 개체였는데 이러한 결과는 제주도에서 혼획 좌초된 바다거북이 우리나라 연안에서 산란행동 을 할 수 있음을 시사하기도 한다.

앞으로도 제주도 연안 해역에서 혼획 및 좌초 되는 바다거북의 개체 수는 점차 증가할 것으로 추정되며, 이에 따라 적절한 모니터링 시스템의 구축 및 상시 모니터링을 통하여 정확한 바다거 북의 동향을 파악하고, 멸종위기에 처한 바다거 북의 보존 계획도 합께 수립되어야 할 것이다. 특히 최근 사회적 이슈가 되고 있는 공공관람형 수족관(public aquarium)에서의 대형 해양동물의 전시에 대한 사회적 갈등에 대한 출구로서 제주 도를 비롯한 우리나라 연안에서 관찰되는 바다거
북의 혼획과 좌초에 대한 공공관람형수족관의 사 회적 기여와 교육적 활동에 대한 적극적인 관심 과 투자가 필요하다고 생각한다(김, 2012).

\section{V. 요 약}

2008년부터 2009년까지 제주도 연안 해역에서 혼획 및 좌초 되는 바다거북의 모니터링을 실시 하였다. 그 결과 푸른바다거북(C. mydas) 12 마리, 붉은바다거북 $(C$ caretta) 3 마리, 매부리바다거북 (E. imbricata) 1 마리, 미확인 종 25마리 등 총 41 마리의 바다거북이 2 년 동안 제주도 연안 해역에 서 관찰되었다. 월별 및 해역별로는 8 월에 제주 도 북서부 연안의 애월읍 해역에서 혼획 및 좌초 빈도가 높았고 2008년 보다 2009년도에 증가하는 경향을 나타내었다. 특히 제주도 북부 해안에 위 치한 애월읍 연안 해역에서 연속적으로 출현 개 체 수가 증가하는 것으로 보아 이 지역은 바다거 북의 색이장 및 생육장이 되고 있을 것으로 추측 된다. 어구별로는 정치망과 자망에서 주로 혼획 되었으며, 수동적 어구 형태인 정치망의 혼획이 높은 것으로 보아 먹이를 쫓아가다가 혼획되는 것으로 판단된다. 이번 연구를 통하여 앞으로도 제주도 연안 해역에 출현하는 바다거북의 개체 수는 점차 증가할 것으로 예측되어 체계적인 모 니터링 시스템 구축이 필요할 것으로 판단된다.

\section{참고 문헌}

김종문(2012). 초등교사의 해양수족관 현장학습에 대한 인식과 해양수족관의 교육적 기능, 수산 해양교육연구 24(3), 459 467.

문대연 - 정민민 · 안용락 - 최석관 · 오봉세 - 김장 근 · 이주·김문진 · 김삼연(2009). 한국 연안의 멸종위기 바다거북의 분포 및 좌초 현황, 한국 수산과학학회지 42(2), 657 663.

정민민 · 문대연 · 김성호 - 김흥수 · 김재우(2012). 우리나라 제주도에 위치한 바다거북 우연산란 장의 환경조건, 수산해양교육연구 24(4), 507 
515.

Balazs, G.H., 1982. Growth rates of immature green turtles in the Hawaiian archipelago, Pages 117-126 in K.A. Bjorndal (ed), Biology and Conservation of Sea Turtles, Smithsonian Inst. Press. Washington, D.C., 583.

Bolton, A.B. and B.E. Witherington, 2003. Loggerhead sea turtles, Washington: Smithsonian Book, 210 217.

Bustard, R.H., 1970. Experimental turtle farmes for Torres Strait Islands, Aust. Fish., 29: $18 \sim 21$.

FAO, 2005. Report of the technical consultation on sea turtle conservation and fisheries, Bangkok, Thailand, 29 November-2 Decomber 2004. FAO Fisheries Report No. 765. Rome, FAO, 31.

Gardner, B., S.J. Morreale, P.J. Sullivan, C.N. Barron and S. Epperly, 2006. Spatio-temporal analyses of loggerhead sea turtle interactions with pelagic fisheries, EOS Trans. Am. Geophys. Union, 87.

IATTC, 2006. Annual Report of the InterAmerican Tropical Tuna Commission, 2004. IATTC, LaJolla, California, USA. 96.

Marquez, M.R., 1990. FAO Species Catalogue,
Vol. 11. Sea Turtles of the World. An annotated and illustrated catalogue of sea turtle species known to data, FAO Fisheries Synopsis, 125, 81.

Moncada, F., F.A. Abreu-Grobois, A. MuhliaMelo, C. Bell, S. Troeeng, K.A. Bjorndal, A.B. Bolten, A.B. Meylan, J. Zurita, G. Espinosa, G. Nodarse, R. Marquez-Millan, A. Foley and L. Ehrhart, 2006. Movement patterns of green turtles (Chelonia mydas) in Cuba and adjacent Caribbean waters inferred from flipper tag recaptures, J. of Herpetology, 40: 22 34.

WCPFC, 2008. Summary Report of the Western and Central Pacific Fisheries Commission, Fifth Regular Session, 8-12 December 2008, Busan, Korea. 206.

Wyneken, J., 2001. Anatomy of sea turtle. NOAA Technical Memorandum NMFS SEFSC, No. 470, 186.

- 논문접수일 : 2012년 08월 30일

- 심사완료일 : 1차 - 2012년 09월 14일 2차 - 2012년 09월 22일

- 게재확정일 : 2012년 09월 24일 